\title{
Work intensity: potential antecedents and consequences
}

\author{
Ronald J. Burke \\ Schulich School of Business, York University, Toronto, Canada \\ Parbudyal Singh \\ School of Human Resource Management, York University, Toronto, Canada, \\ and \\ Lisa Fiksenbaum \\ Department of Psychology, Faculty of Health, York University, Toronto, Canada
}

\begin{abstract}
Purpose - The purpose of this exploratory research is to examine the relationship of a measure of work intensity with potential antecedents and consequences.

Design/methodology/approach - A questionnaire was developed and pre-tested. It included a new 15-item measure of work intensity. Data were collected from 106 respondents enrolled in three university business courses using anonymously completed questionnaires. Regression and factor analyses were used in developing the measure and testing the relationships.

Findings - The 15-item measure of work intensity was found to have high internal consistency and reliability. Work intensity was significantly related to respondents' organizational level and work status. In addition, respondents indicating higher levels of work intensity also reported working more hours, a higher workload, and greater job stress. Work intensity was unrelated to organizational values supporting work-personal life imbalance, three workaholism components, or to indicators of work engagement. Factor analysis of the work intensity measure produced three factors: emotional demands, job demands, and time demands, the first two were fairly consistently related to other study variables, whereas time demands was not.

Research limitations/implications - The sample was relatively small and the data were collected using self-reports. The design was cross-sectional, thus limiting causal inferences.

Practical implications - Managers will find the study useful in assessing the effects of work intensity and working long hours for employees, including stress levels and work engagement.

Originality/value - The study developed a work intensity measure and examined its properties and correlates, something that is lacking in the literature.
\end{abstract}

Keywords Job satisfaction, Hours of work, Family friendly organizations, Mental illness, Overwork

Paper type Research paper

\section{Introduction}

Issues related to work, including long work hours and work intensity, have been attracting increasing attention from scholars and practitioners (Bell and Freeman, 2001; Burchell and Fagan, 2004; Burke, 2007; Eastman, 1998; Filer et al., 1996; Green, 2001; Feldman, 2002; Ng et al., 2007; Hochschild, 1997; Schor, 1991). This interest is not surprising given the importance of work in the lives of people. Work is an important

Preparation of this manuscript was supported in part by York University and the School of Human Resources Management, York University. 
economic, social and psychological ingredient of human life. It provides an income for goods and services needed by employees and their families, and it helps socially with group identification and a sense of belonging. Work can also provide enjoyment, satisfaction, and a sense of accomplishment, achievement and success (O'Toole and Lawler, 2006). Overwork may also have negative consequences for employees, their families, organizations and society (Dembe et al., 2005; Feldman, 2002; Sparks et al., 1997; Van der Hulst, 2003). Recognizing the effects of overwork, the European Union's Working Time Directive, passed in 2000, provides workers with the right to have 11 hours of rest a day and a limit to a 48 hour work week, if the worker so chooses (Russell, 2007). In a recent Harvard Business Review article, Hewlett and Luce (2006) report on a growing trend of employees working 70-hour work weeks and its potential effects. This issue has attracted some scholarly attention in a few developed countries/regions including the USA (Hochschild, 1997; Schor, 1991), and Europe (Burchell and Fagan, 2004; Green, 2001). However, as Feldman (2002, p. 34) notes, "although the trend toward longer work weeks has been well documented..., the reasons for this trend are still not fully understood." Thus, there is a need for further research.

This study is significant for both theoretical and practical reasons. Theoretically, we examine a work intensity measure and consider its properties and correlates, something that is lacking in the literature. Then we assess some of antecedents and consequences of work intensity. The study of work hours and work intensity is important for a number of practical reasons as well. At the individual level, there are concerns that working long hours can have negative physiological outcomes. Employees can get sick -insomnia, fatigue, irritability, to name a few - and these not only affect the individual's well-being, but that of their families and co-workers (Buell and Breslow, 1960; Dembe et al., 2005; Sparks et al., 1997; Van der Hulst, 2003). At the organizational level, two contrasting sets of outcomes are possible. First, these negative psychological and physiological effects threaten the smooth and efficient functioning of the organization, and eventually, its financial viability. Much of the research regarding long working hours has called for organizations to take note and deal with likely negative outcomes such as stress, burnout, and turnover (Burke, 2007). The Japanese have even coined a term used to describe death resulting from overwork - karoshi (Uehata, 1991; Kofodimos, 1993). On the other hand, given the appropriate context, hard work can be satisfying for employees who are motivated by such pressure, and there may be associated organizational rewards for the individual and productivity gains for the organization.

In the next section, we give a conceptual overview of the work intensity issue, the purpose of the study, and theorize on possible correlates and consequences of work intensity. This is followed with a discussion of the methods used in this study and the results. In our discussion section, we offer possible reasons for the findings, discuss implications for organizations, and suggest areas for future research.

\section{Conceptual background}

"Working hard" may be conceptualized as comprising a time component (e.g. hours worked) and an intensity perspective (e.g. how intense is the effort during the time worked). First, work has historically been viewed as the amount of hours the employee spends on the job. The time aspect has generated considerable debate (Brett and Stroh, 
2003; Maume and Bellas, 2001; Schor, 1991). While the time worked in the average work week has been relatively stable (Galarneau et al., 2005), it is unevenly distributed among workers. The longer work hours of some employees, including managers and professionals (Golden, 2007), are balanced by the increase in the number of employees working fewer hours per week because of choice or the hourly limits set by non-standard employment (Zeytinoglu and Cooke, 2005; Cranford et al., 2003). Blue-collar workers now tend to work fewer hours while white-collar employees are working longer hours. The time aspect of "working hard" has attracted most of the research attention to date.

Work intensity, on the other hand, is a construct that is not well developed in the research literature. There is also no overarching theory used to study work intensity. Scholars from different backgrounds and disciplines have used different theories to capture aspects of this phenomenon (Bell and Hart, 1999; Burke, 2007; Eastman, 1998; Filer et al., 1996; Hewlett and Luce, 2006; Hochschild, 1997). It is sometimes conceptualized as an effort-related activity. In this regard, it is very similar to the "work effort" concept discussed in the economics literature. For instance, Green (2001, p. 56) described work effort as:

[...] the rate of physical and/or mental input to work tasks performed during the working day ... in part, effort is inversely linked to the "porosity" of the working day, meaning those gaps

between tasks during which the body or mind rests.

Obviously, it would be difficult to measure such effort objectively; it can only be determined through self-reports, or extraordinarily well-controlled laboratory experiments. Burchell and Fagan (2004) used the "speed of work" to mean work intensity, and reported that Europeans were working more intensely (2000 compared to 1991). Green (2001) focused on "effort change", where respondents were asked to compare their current jobs with those held five years earlier.

Green and McIntosh (2001) found that, among European countries, Britain experienced the fastest rise in work effort in the early to mid-1990s, while in Western Germany, Denmark and Greece, there was little effort intensification. Effort was higher in jobs that used computers more frequently, and except for Britain, higher in private sector than public sector jobs. Effort had also increased in countries where union membership had declined (Green and McIntosh, 1998).

\section{Purpose of the study}

The present exploratory study reports on the development of a measure of work intensity, some of its properties, and its relationship with potential antecedents and consequences. Given the exploratory nature of this study, we do not offer an extensive literature review and formal hypotheses. Rather, we address some "general hypotheses" or expectations. First, we hypothesize that work intensity might comprise more than one component. Green (2004a, 2005) suggests that pace, effort, and affect are likely to be included in assessments of work intensity. Second, we hypothesize that since work intensity characterizes one's job, there would be few individual differences and workplace culture correlates of it. That is, the nature of one's job (responsibilities, technologies) rather than one's personal characteristics would be associated with reported levels of work intensity. Green (2004b) found that in Britain in the 1990s, both technological and organizational changes were important sources of 
work intensification. And Burchell et al. (1999) found an association between levels of job insecurity and feelings of work intensification among workers in Britain. Third, we expect that higher levels of work intensity would be associated with more negative outcomes but not with more positive outcomes. Green and McIntosh (2001), for example, suggest that work intensification is likely to be associated with physical exhaustion and mental stress.

Overall, we theorize the work intensity is influenced by two inter-related sets of determinants: those internal and external to the employee. An employee can be intrinsically motivated to work "hard" because of personal factors, such as being a workaholic. The external or environmental variables determine the work context. These contextual variables, such as organizational values, may affect work intensity. Simply put, individuals who choose to work hard may do so because of a psychological inclination, or an inner drive to maximize satisfaction that may be coupled with a desire to fulfill personal needs and the organizational context. The consequences of work intensity (positive or negative for the employee, organization and society), such as psychological wellbeing/stress and work engagement, are influenced by the specific dynamics of the environment. That is, a strong psychological desire to work intensely may produce positive outcomes for the employee and employer (e.g. increased satisfaction and work engagement), if the work environment is conducive to personal effort and is aligned to individual needs. On the other hand, negative outcomes, such as stress and fatigue, will be more pronounced in a coercive, non-rewarding work environment.

We concede that there are numerous other factors that may drive work intensity; however, in this study we only tested an initial set because of the exploratory nature of the study and the uniqueness of the work intensity measure developed. Figure 1 captures the relationships tested in this study in a diagrammatic model. Overall, work intensity is influenced by personal (internal to the employee) and work situation (external) factors. At the personal level, the intrinsic variables (e.g. workaholism) may motivate employees to work hard. The work-situation/job-related or contextual variables, such as organizational values and life experiences, may directly affect work

Figure 1.

A model of the antecedents and consequences of work intensity
Personal Characteristics

- Workaholism

- Personal demographics (gender, etc.)

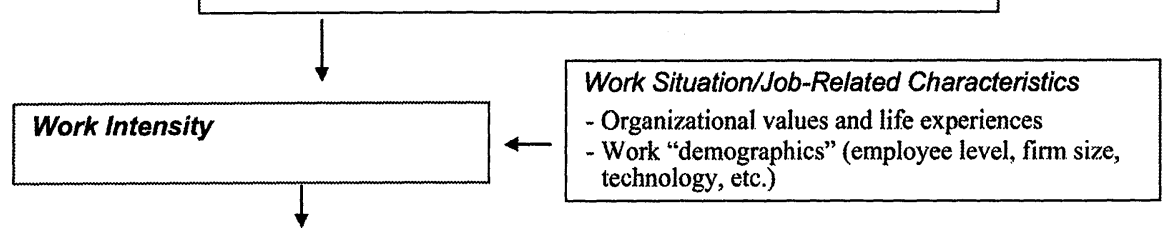

Outcomes/Correlates

- Work engagement (vigor, absorption, dedication)

- Stress

- Workload

- Work hours 
intensity. The consequences of work intensity include work engagement, hours
worked, and stress.

\section{Methodology}

Respondents

Table I shows the demographic characteristics of the respondents. Most were between 21 and 25 years of age ( 57 percent), were single ( 83 percent), were working part-time at the time of the research ( 75 percent), were in non-management positions (67 percent), had one year or less of job tenure (47 percent), between two to five years of organizational tenure (49 percent), and worked between 16 and 30 hours per week (44 percent).The average age of the sample was 25 years, with respondents average full-time work experience being three years and 33 percent holding management positions.

\section{Procedure}

A questionnaire was developed that included the work intensity measure, as well as several other items and scales potentially related as antecedents and consequences.

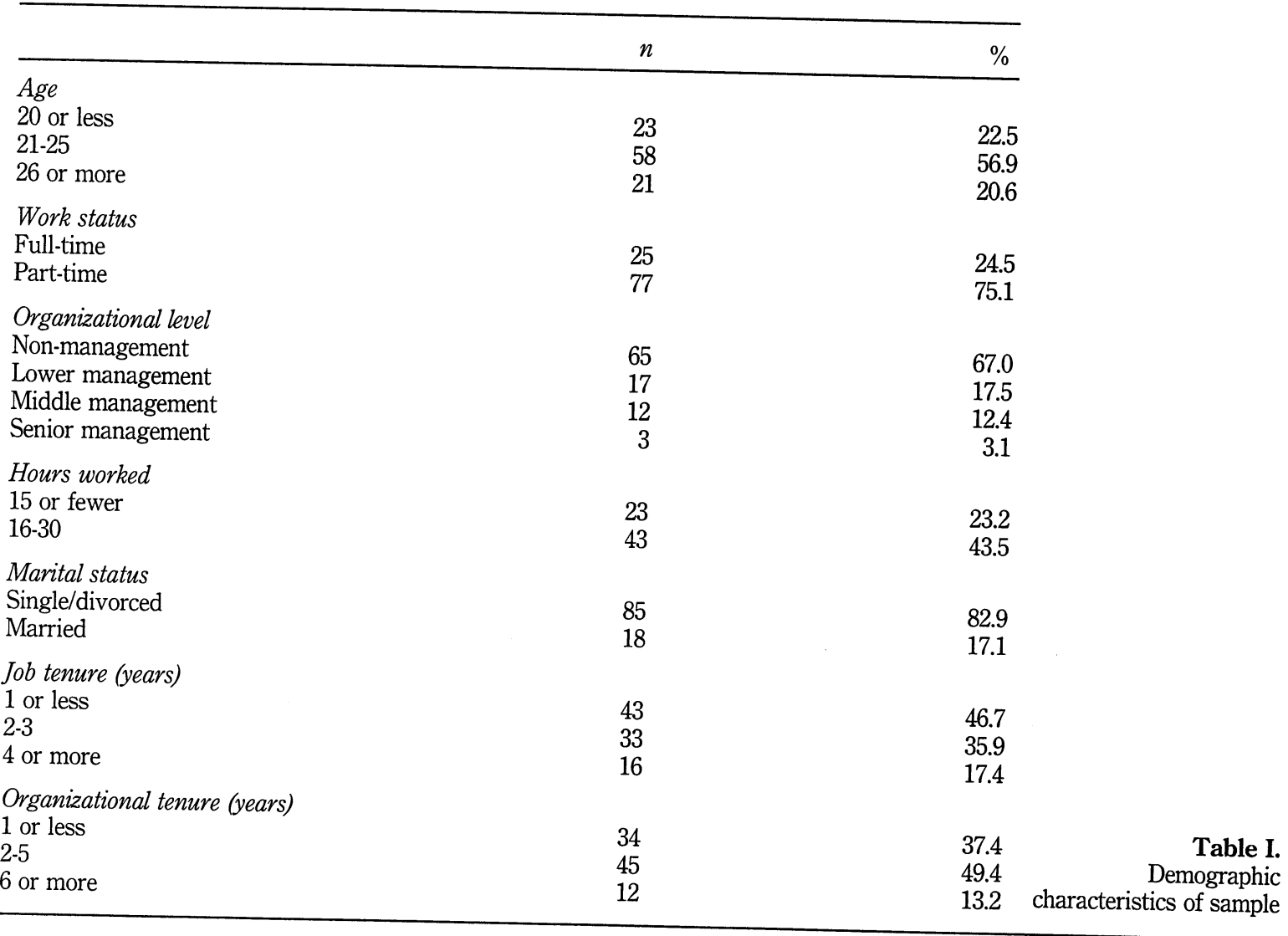


The questionnaire was distributed to students in three university classes, selected randomly, at a large Canadian university. Of the 142 questionnaires distributed, 108 were returned, a response rate of 76 percent.

\section{Measures}

Personal and work situation characteristics. A number of personal demographic (e.g. age, marital status) and work situation characteristics (e.g. job tenure, organizational level) were assessed by single items.

Hours worked. Hours worked was assessed by a single item. Respondents indicated the number of hours they worked in a typical week.

Workaholism components. Three workaholism components identified by Spence and Robbins (1992) were included; their measures of these components were also used. Respondents indicated their level of agreeableness on a five-point Likert scale ranging from Strongly agree (1) to Strongly disagree (5). Work involvement (Alpha $=0.41$ ) had eight items. Items included: "I get bored and restless on vacations when I haven't anything productive to do", and, "I spend my free time on projects and other activities." Feeling driven to work because of internal pressures had seven items (Alpha $=0.84$ ), including "I often feel that there is something inside me that drives me to work hard", and, "I feel guilty when I take time off work." Work enjoyment had ten items (alpha $=0.78$ ), including "I like my work more than most people do," and "My job is more like fun than work."

Workload. Workload was measured by a five item scale $($ Alpha $=0.81)$ developed by Spector and Jex (1998). Respondents were asked the frequency of behaviours ranging from less than once per month (scored as 1) to several times per day (scored as a 5). Examples of questions included: "How often is there a great deal of work to be done?" and "how often does your job leave you with little time to get things done?"

Work intensity. Work intensity was assessed by a 15-item scale (Alpha $=0.85$ ). Some items were taken from Hewlett and Luce (2006) while others were developed by the researchers. Respondents were asked to state to what extent certain work descriptions reflected their jobs on a five-point Likert scale ranging from "does not describe my job at all (1) to "describes my job perfectly" (5). Items included: "an unpredictable flow of work", "availability to clients 24/7", and a "large scope of responsibility that amounts to more than one job".

Organizational values. Organizational values supporting work-personal life balance/imbalance were measured by two scales developed by Kofodimos (1993). One scale had eight items assessing organizational values supporting work-personal life imbalance; the other scale had nine items and assessed values supporting work-personal life balance. These two scales were combined, reversing scores on the imbalance scale (Alpha $=0.76)$. Respondents were asked to rate to what extent the items were positively valued in their organization or represent desirable qualities in managers on a five-point Likert scale from Strongly agree (1) to Strongly disagree (5); the items included: "accepting work-related phone calls at home or weekends", "consistently spending long hours at the office," and "taking your full vacation allotment."

Job stress. Job stress was measured by a nine-item scale $($ alpha $=0.81)$ developed by Spence and Robbins (1992). Items included: "I often wake up worrying about work," "I worry a lot about all the work I have to do and how I'll get it done," and "sometimes I 
feel like my work is going to overwhelm me." The five-point Likert-scale ranged from Strongly agree (1) to Strongly disagree (5).

Work engagement. Three aspects of work engagement were assessed using scales developed by Schaufeli et al. (2002). Vigor was measured by six items (Alpha = 0.84). An item was "At my work I feel bursting with energy." Absorption was assessed by six items (Alpha $=0.81$ ). One item was "I am immersed in my work." Dedication was assessed by five items (Alpha $=0.70$ ). An item was "I am proud of the work that I do." Respondents indicated their agreement with each item on a five-point Likert scale ( 1 = Strongly disagree, $3=$ Neither agree nor disagree; $5=$ Strongly agree).

\section{Results}

\section{Measure of work intensity}

The measure of work intensity was found to have an acceptable level of internal consistency reliability (Alpha $=0.85$ ). An exploratory factor analysis was then undertaken using the Principal Axis Varimax Rotation procedure. Three factors emerged accounting for 54 percent of the common variance. These factors and their labels were: Time demands (four items, alpha $=0.72$ ): items included, "work-related events outside of regular work hours", and "availability to clients 24/7"; Emotional demands (five items, Alpha $=0.80$ ): items included, "work demands a lot from me emotionally", and Job demands (three items, Alpha $=0.75$ ), items included "large scope of responsibility that amounts to more than one job", and "fast-paced work under tight deadlines". These three factors were themselves significantly and positively inter-correlated: Time demands and Emotional demands $(r=0.42, p<0.001)$, Time demands and Job demands $(r=0.20, p<0.05)$, and Emotional Demands and Job demands $(r=0.43, p<0.001)$.

\section{Correlates of work intensity}

Table II presents the correlations of the work intensity measure with potential antecedents and consequences. The following results are offered in summary. About half the correlations were significantly different from zero $(p<0.05)$. First, work intensity was significantly and positively correlated with age and marital status (these also being significantly correlated). Second, work intensity was positively and significantly correlated with work status (full-time being higher), and organizational level. Third, work intensity was significantly correlated with only one of the three workaholism components (work involvement). Fourth, work intensity was positively and significantly correlated with hours worked, workload and levels of job stress. Fifth, work intensity was significantly correlated with only one of the three work engagement measures (absorption) but negatively.

\section{Correlates of the three work intensity factors}

Table III shows the correlations of the three work intensity scale factors (time demands, emotional demands, and job demands) and various potential antecedents and consequences. The following comments are offered in summary. First, not surprisingly, the general pattern of results obtained using the full work intensity measure (see Table II) was present when the three work intensity factors were analyzed separately. Second, emotional demands produced the most statistically significant relationships, followed by job demands, with time demands having the 
Variables

Work intensity correlates

Personal demographics

Age

$0.23^{*}$

Job tenure

0.10

Organizational tenure

Marital status

0.10

Work status

0.22

Work situation characteristics

Organizational level

Hours worked

Workload

Organizational values

Job stress

$0.26^{*}$

Workaholism components

Work involvement

$0.47^{* *}$

$0.45^{* *}$

$0.36^{* *}$

0.12

Feeling driven to work

$0.40^{* *}$

Work enjoyment

$0.20^{*}$

0.13

Engagement

Vigor

Dedication

Table II.

Correlates of work

Absorption

$-0.15$

$-0.13$

Notes: ${ }^{*} p<0.05 ;{ }^{* *} p<0.001 ; n$ ranges from 80 to 106

\begin{tabular}{|c|c|c|c|}
\hline Correlates & Emotional demands & Job demands & Time demands \\
\hline \multicolumn{4}{|l|}{ Personal demographics } \\
\hline Work status & $0.35^{*}$ & $0.27^{*}$ & 0.14 \\
\hline Organizational level & $0.46^{* *}$ & $0.25^{*}$ & $0.34^{* *}$ \\
\hline \multicolumn{4}{|l|}{ Work situation } \\
\hline Work hours & $0.38^{* *}$ & $0.42^{* *}$ & 0.12 \\
\hline Workload & $0.46^{* *}$ & $0.25^{*}$ & $0.34^{* *}$ \\
\hline Organizational values & 0.16 & 0.28 & 0.10 \\
\hline Job stress & $0.47^{* *}$ & $0.41^{* *}$ & 0.00 \\
\hline \multicolumn{4}{|l|}{ Workaholism components } \\
\hline Work involvement & 0.18 & 0.18 & 0.01 \\
\hline Feeling driven to work & $0.23^{*}$ & $0.18^{*}$ & -0.12 \\
\hline Work enjoyment & 0.13 & 0.12 & -0.04 \\
\hline \multicolumn{4}{|l|}{ Work engagement } \\
\hline Vigor & $-0.19^{*}$ & 0.03 & -0.06 \\
\hline Dedication & -0.14 & -0.05 & -0.05 \\
\hline Absorption & -0.23 & -0.03 & -0.13 \\
\hline \multicolumn{4}{|c|}{ Notes: ${ }^{*} p<0.05 ;{ }^{* *} p<0.001 ; n$ ranges from 80 to 106} \\
\hline
\end{tabular}

Table III.

Correlates of work intensity factors 
fewest statistically significant relationships. Third, time demands in fact had only one statistically significant relationship with any of the other potential antecedents and consequences, vis-à-vis workload. Fourth, respondents scoring higher on both emotional demands and job demands generally reported working more hours, having heavier workloads, and more job stress but work intensity tended to be independent of levels of their work engagement.

\section{Analysis strategy}

In order to better understand the sources of work intensity and to examine our general hypotheses, a hierarchical regression analysis was first undertaken in which the measure of work intensity was regressed on two blocks of predictors entered in a specified order. The first block of predictors $(n=2)$ consisted of personal demographics (e.g. age, marital status). The second block of predictors $(n=4)$ included work situation characteristics (e.g. work status, organizational level, job tenure). When a block of predictors accounted for a significant amount or increment in explained variance on a given criterion variable $(p<0.05)$, individual items of measures within such blocks having significant and independent relationships with these criterion variables were then identified $(p<0.05)$. This analysis controls for the relationships of both personal demographics and work situation characteristics before examining the relationship of the work intensity measure and other variables of interest.

\section{Predictors of work intensity}

Table IV shows the results of a hierarchical regression analysis in which the measure of work intensity was regressed on two blocks of predictors: personal demographics and work situation characteristics. Work situation characteristics accounted for a significant increment in explained variance on the work intensity measure $(B=0.50)$; individuals at higher organizational levels indicated greater work intensity $(B=0.38)$.

Additional hierarchical regressions were carried out in which a third block of predictors were added to the two blocks of predictors considered in Table IV. Two separate regressions were undertaken in which organizational values supporting work-personal life imbalance/balance, and the three workaholism components were entered as predictors of work intensity. The three workaholism components and the measure of organizational values supporting imbalance/balance had no relationship with the work intensity indicator.

\section{Consequences of work intensity}

Table $\mathrm{V}$ shows the results of hierarchical regression analyses in which six work outcomes were separately regressed on the three blocks of predictors described above. The following comments are offered in summary. First, all three blocks of predictors

\begin{tabular}{lccccc}
\hline Work intensity $(n=87)$ & $R$ & $R^{2}$ & Change $R^{2}$ & $p$ & \\
\hline Personal demographics & 0.28 & 0.08 & 0.08 & 0.05 & Table IV. \\
Work situation characteristics & 0.50 & 0.25 & 0.17 & 0.01 & Predictors of work \\
Organizational level & $(0.38)$ & & & & intensity \\
\hline
\end{tabular}




\begin{tabular}{|c|c|c|c|c|c|}
\hline & Consequences & $R$ & $R^{2}$ & Change $R^{2}$ & $p$ \\
\hline & $\begin{array}{l}\text { Work hours }(\mathrm{n}=86) \\
\text { Personal demographics } \\
\text { Age }(0.29)\end{array}$ & 0.70 & 0.49 & 0.49 & 0.001 \\
\hline & $\begin{array}{l}\text { Work situation characteristics } \\
\text { Work status }(0.44)\end{array}$ & 0.83 & 0.68 & 0.19 & 0.001 \\
\hline & Work intensity $(0.19)$ & 0.84 & 0.71 & 0.03 & 0.01 \\
\hline & $\begin{array}{l}\text { Workload }(\mathrm{n}=87) \\
\text { Personal demographics } \\
\text { Age }(0.39)\end{array}$ & 0.32 & 0.10 & 0.10 & 0.001 \\
\hline & Work situation characteristics & 0.47 & 0.22 & 0.12 & 0.05 \\
\hline & Work intensity $(0.22)$ & 0.51 & 0.26 & 0.04 & 0.05 \\
\hline & $\begin{array}{l}\text { Job stress }(\mathrm{n}=87) \\
\text { Personal demographics } \\
\text { Age }(0.34) \\
\text { Work situation characteristics } \\
\text { Work intensity }(0.44)\end{array}$ & $\begin{array}{l}0.29 \\
0.40 \\
0.55\end{array}$ & $\begin{array}{l}0.08 \\
0.16 \\
0.30\end{array}$ & $\begin{array}{l}0.08 \\
0.08 \\
0.14\end{array}$ & $\begin{array}{l}0.05 \\
\text { NS } \\
0.001\end{array}$ \\
\hline & $\begin{array}{l}\text { Vigor }(\mathrm{n}=87) \\
\text { Personal demographics } \\
\text { Work situation characteristics } \\
\text { Work intensity }\end{array}$ & $\begin{array}{l}0.29 \\
0.40 \\
0.42\end{array}$ & $\begin{array}{l}0.08 \\
0.16 \\
0.18\end{array}$ & $\begin{array}{l}0.08 \\
0.08 \\
0.02\end{array}$ & $\begin{array}{l}0.05 \\
\text { NS } \\
\text { NS }\end{array}$ \\
\hline & $\begin{array}{l}\text { Dedication }(\mathrm{n}=87) \\
\text { Personal demographics } \\
\text { Work situation characteristics } \\
\text { Work intensity }\end{array}$ & $\begin{array}{l}0.32 \\
0.46 \\
0.46\end{array}$ & $\begin{array}{l}0.10 \\
0.21 \\
0.21\end{array}$ & $\begin{array}{l}0.10 \\
0.11 \\
0.00\end{array}$ & $\begin{array}{l}0.01 \\
0.05 \\
\text { NS }\end{array}$ \\
\hline $\begin{array}{l}\text { Table V. } \\
\text { Consequences of work } \\
\text { intensity }\end{array}$ & $\begin{array}{l}\text { Absorption }(\mathrm{n}=87) \\
\text { Personal demographics } \\
\text { Work situation characteristics } \\
\text { Work intensity }\end{array}$ & $\begin{array}{l}0.45 \\
0.46 \\
0.47\end{array}$ & $\begin{array}{l}0.20 \\
0.21 \\
0.22\end{array}$ & $\begin{array}{l}0.20 \\
0.01 \\
0.01\end{array}$ & $\begin{array}{l}0.001 \\
\text { NS } \\
\text { NS }\end{array}$ \\
\hline
\end{tabular}

accounted for a significant amount or increment in explained variance on work hours. Older respondents, respondents working full-time, and respondents in more "work intense" jobs worked more hours $(B s=0.29,0.44$ and 0.19 , respectively). Second, all three blocks of predictors accounted for a significant amount or increment in explained variance of workload. Older respondents and respondents working in more "work intense" jobs reported greater workloads ( $B \mathrm{~s}=0.39$ and 0.22 , respectively). Third, two blocks of predictors accounted for a significant amount or increment in explained variance on self-reported job stress. Older respondents and respondents holding more "work intense" jobs reported higher levels of job stress $(B \mathrm{~s}=0.34$ and 0.44 , respectively).

Fourth, consistent with the general hypotheses underlying this research, although personal demographic and work situation characteristics accounted for a significant amount or increment in explained variance of one or more of the three measures of work engagement, work intensity was found to have no relationship with any of the three work engagement measures. 


\section{Discussion}

This exploratory study examined a measure of work intensity, its properties, and its relationship with other variables. It was hypothesized that work intensity would reflect aspects of one's one's job more strongly than stable individual difference factors or intensity one's organizational culture. In addition, it was hypothesized that work

The measure of work intensity had dissatisfaction but not joy or engagement. it produced meaningful factors suggesting internal consistency reliability. In addition, dimensions.

Work intens of work demsity, as expected, was positively and significantly related with indicators hours, and a heavier. full-time work status, higher organizational level, longer work developed heavier perceived workload) providing construct validation of our newly to levels of job tre. In addition, work intensity was positively and significantly related large samples (Green (see Tables II and V), consistent with longitudinal results using workaholic (Green, 2008). Interestingly, work intensity tended to not be related to it is a different construct), work-personal construct), or organizational values perceived to be reflective of negatively related to indicato. Finally, work intensity was independent, but not enjoyment scale of th indicators of work engagement and satisfaction, using the work find that work intensity working longer hours, however.

These results suggest that wo of one's specific job requirements intensity is likely to be a property or characteristic workloads, longer work hours and highes responsibilities associated with greater affected by the larger organization, higher levels of job stress. Work intensity is not engagement. Fur organization's cultural values and has little impact on one's work satisfaction), psychological should include indicators of one's work attitudes (e.g. job work-family conflict and facilitation.

There are several theoretical and practical implications of this study. As mentioned in the introduction, in developing a measure of work intensity, this study adds a new theoretical dimension to the study of work hours and work intensity. It also opens new frontiers for research on these phenomena. There are implications for society and practitioners as well. First, workplace health issues are beginning to significantly affect employees and by extension, organizations and the economy (Burchell and Fagan, 2004; Burke, 2007; Ng et al., 2007; Hochschild, 1997). As we found in this research, stress, a significant aspect of workplace health, is related to work intensity. Organizations may have to deal with this issue proactively, such as allowing for hours of rest, legislated in the European Union. Managers may also have to radically re-design jobs and re-visit the workload issue so as to decrease work intensity.

Some limitations of this research should be acknowledged to put the findings in context. First, the sample was relatively small. Second, the sample as a whole, did not work long hours. Third, all data were collected using self-report questionnaires raising the possibility of response set tendencies and common method bias. Fourth, cross-sectional data were used making it difficult to address issues of causality. Fifth, one of the measures had a level of internal consistency reliability below the generally
accepted level of 0.70 . 
Future research on work intensity should involve larger samples of respondents working full time in jobs that permit or require working long hours. In addition, our knowledge of the effects of work hours and work intensity would be increased by including a wider array of potential individual and organizational antecedents and consequences. These might include individual levels of achievement, motivation, job satisfaction, conscientiousness, and job insecurity and organizational indicators of staffing levels or downsizing as well as competitive pressures. We believe that work intensity, though likely to be moderately and positively correlated with hours worked will emerge as a stronger predictor of work and well-being outcomes than number of hours worked.

\section{References}

Bell, D. and Hart, R. (1999), “Unpaid work”, Economica, Vol. 66, pp. 271-90.

Bell, L. and Freeman, R.B. (2001), "The incentive for working hard: explaining hours worked differences in the USA and Germany", Labour Economics, Vol. 8, pp. 181-202.

Brett, J.M. and Stroh, L.K. (2003), "Working 61 plus hours a work: why do managers do it?", Journal of Applied Psychology, Vol. 88, pp. 67-78.

Buell, P. and Breslow, P. (1960), "Mortality from coronary heart disease in California men who work long hours", Journal of Chronic Disease, Vol. 11, pp. 615-26.

Burchell, B. and Fagan, C. (2004), "Gender and the intensification of work: evidence from the European Working Conditions survey", Eastern Economic Journal, Vol. 30, pp. 627-42.

Burchell, B.J., Day, D., Hudson, M., Ladipo, D., Mankelow, R., Nolan, J., Reed, H., Wichert, I.C. and Wilkinson, F. (1999), Job Insecurity and Work Intensification: Flexibility and the Changing Boundaries of Work, Joseph Rowntree Foundation, York.

Burke, R.J. (2007), Research Companion to Working Hours and Work Addiction, Edward Elgar, Chichester.

Cranford, C., Vosko, L. and Zukevich, N. (2003), "The gender of precarious employment in Canada", Relations Industrielles, Vol. 58 No. 3, pp. 454-79.

Dembe, A.E., Erickson, J.B., Delbos, R.G. and Banks, S.M. (2005), "The impact of overtime and long work hours on occupational injuries and illnesses: new evidence from the United States", Occupational and Environmental Medicine, Vol. 62, pp. 588-97.

Eastman, W. (1998), "Working for position: women, men, and managerial work hours", Industrial Relations, Vol. 11, pp. 51-66.

Feldman, D. (2002), "Managers' propensity to work longer hours: a multi-level analysis", Human Resource Management Review, Vol. 12, pp. 339-57.

Filer, R., Hammermesh, D. and Rees, A. (1996), The Economics of Work and Pay, Harper Collins, New York, NY.

Galarneau, D., Maynard, J. and Lee, J. (2005), Whither the Workweek?, Cat. No. 75-001-XIE, Statistics Canada, Ottawa.

Golden, L. (2007), "How long? The history of economic and cultural factors behind working hours and overwork", in Burke, R.J. (Ed.), Research Companion to Working Time and Work Addiction, Edward Elgar, Cheltenham, pp. 36-57.

Green, F. (2001), "It's been a hard day's night: the concentration and intensification of work in late twentieth-century Britain", British Journal of Industrial Relations, Vol. 39, pp. 53-80.

Green, F. (2004a), “Why has effort become more intense?”, Industrial Relations, Vol. 43, pp. 709-41. 
Green, F. (2004b), "Work intensification, discretion and the decline in wellbeing at work", Eastern
Economic Journal, Vol. 30 .

Green, F. (2005), Demanding Work: The Paradox of Job Quality in the Affluent Economy,
Princeton University Press, Princeton, NJ.

Green, F. (2008), "Work effort

Cooper, C.L. (Eds), The Long Work wellbeing in the age of affluence", in Burke, R.J. and Emerald Group Publishing, Bingley.

Green, F. and McIntosh, S. (1998), "Union power, costs of job loss and working effort", Industrial
and Labor Relations Review, Vol. 1, pp. 363-83 and Labor Relations Review, Vol. 1, pp. 363-83.

Green, F. and McIntosh, S. (2001), "The intensification of work in Europe", Labor Economics,
Vol. 8, pp. 291-308.

Hewlett, S. and Luce, C. (2006), "Extreme jobs: the dangerous allure of the 70-hour work week",
Harvard Business Review, December,

Metropolitan Books, New York, NY.

Kofodimos, J. (1993), Balancing Act, Jossey-Bass, San Francisco, CA.

Maume, D. and Bellas, M. (2001), "The overworked American or the time bind?", American
Behavioral Scientist, Vol. 44, pp. 1137-56.

$\mathrm{Ng}$, T., Sorensen, K. and Feldman, D. (2007), "Dimensions, antecedents, and consequences of Workaholism: a conceptual integration and extension", Journal of Organizational Behavior,

O'Toole, J. and Lawler, E. (2006), The New American Workplace, Palgrave Macmillan, San
Francisco, CA.

Russell, K. (2007), "Working time: is it working out?", British Journal of Administrative
Management, Februat engagement and burnout: a twalez-Roma, V. and Bakker, A.B. (2002), "The measurement of Happiness Studies, Vol. 3, pp. 71-92.

Schor, J.B. (1991), The Overworked American: The Unexpected Decline of Leisure, Basic Books,
New York, NY.

Sparks, K., Cooper, C.L., Fried, Y. and Shirom, A. (1997), "The effects of hours of work on health:
a meta-analytic review", Journal of Occupational and Orgats a meta-analytic review", Journal of Occupational and Organizational Psychology, Vol. 70,
pp. 391-408.

Spector, P.E. and Jex, S.M. (1998), "Development of four self-report measures of job stressors and strain: interpersonal conflict at work scale, organizational constraints scale, quantitative workload inventory, and physical symptoms inventory", Journal of Occupational Health
Psychology, Vol. 3 p. 356-67. Spence, J.T. and Robbins, A.S. (1992), "Workaholism: definition, measurement, and preliminary
results", Journal of Personality Assessment, Vol. 58, pp. 160-78.

Uehata, T. (1991), "Long working hours and occupational stress-related cardiovascular attacks among middle-aged workers in Japan", Journal of Human Ergonomics, Vol. 20, pp. 147-53. Van der Hulst, M. (2003), "Long work hours and health", Scandinavian Journal of Work,
Environment and Health, Vol. 29, pp. 171-88.

Zeytinoglu, I. and Cooke, G. (2005), "Non-standard work and benefits", Relations Industrielles,
Vol. 60 No. 1, pp. 29-60. 


\begin{abstract}
About the authors
Ronald J. Burke is one of Canada's most prolific researchers. His work has focused on the relationship between the work environment and the individual's overall wellbeing, and over the past 30 years he has written articles for numerous academic and professional journals. In addition to his research and teaching activities, he was the Founding Editor of the Canadian Journal of Administrative Sciences. He has served on the editorial board of a dozen journals. He has published over 500 journal articles. He has also edited or co-edited 27 books. He previously held the Imperial Life Professorship in Organizational Behavior and was a Senior Research Fellow at the National Centre for Management Research and Development, School of Business Administration, The University of Western Ontario.

Parbudyal Singh is an Associate Professor of Human Resource Management at York University, Toronto. His research covers emerging issues in human resources management and labor relations. He has published more than 60 refereed publications, many in top refereed journals such as Industrial Relations, Journal of Labor Research, Management International Review, Comparative Labor Law Journal, Relations Industrielles, Journal of Vocational Behavior, and the Human Resource Management Review. Parbudyal Singh is the corresponding author and can be contacted at: singhp@yorku.ca

Lisa Fiksenbaum is currently a doctoral candidate in the Department of Psychology, York University in Toronto, Canada. Her work focuses on the work-family interface, stress and health, and research/statistical methods.
\end{abstract}

